\title{
Baicalin Maintains Late-Stage Functional Cardiomyocytes in Embryoid Bodies Derived from Murine Embryonic Stem Cells
}

\author{
Meilin Tang ${ }^{\mathrm{a}}$ Mengmeng Yin ${ }^{\mathrm{a}}$ Ming Tang ${ }^{\mathrm{a}}$ Huamin Liang ${ }^{\mathrm{a}}$ Chong Yu ${ }^{\mathrm{a}}$ Xinwu Hu ${ }^{\mathrm{a}}$ \\ Hongyan Luo Birte Baudis $^{b}$ Moritz Haustein ${ }^{b, c}$ Markus Khalilc Tomo Šarićc Jürgen \\ Hescheler ${ }^{b}$ Jiaoya $\mathrm{Xi}^{\mathrm{a}}$
}

\begin{abstract}
aDepartment of Physiology and Chinese-German Stem Cell Center, Tongji Medical College, Huazhong University of Science and Technology, The Key Laboratory for Drug Target Researches and Pharmacodynamic Evaluation of Hubei Province, Wuhan, Hubei, China; 'Institute for Neurophysiology, University of Cologne, Cologne, Germany; 'Department of Pediatric Cardiology, University of Cologne, Cologne, Germany
\end{abstract}

\section{Key Words}

Embryonic stem cells • Cardiomyocytes • Baicalin • Differentiation

\begin{abstract}
Background/Aims: Low efficiency of cardiomyocyte (CM) differentiation from embryonic stem (ES) cells limits their therapeutic use. The objective of this study was to investigate the effect of baicalin, a natural flavonoid compound, on the in vitro cardiac differentiation of murine ES cells. Methods: The induction of ES cells into cardiac-like cells was performed by embryoid body (EB)-based differentiation method. The electrophysiological properties of the ES cell-derived CMs (ES-CMs) were measured by patch-clamp. The biomarkers of ES-CMs were determined by quantitative RT-PCR and immunofluorescence. Results: Continuous baicalin treatment decreased the size of EBs, and increased the proportion of $\alpha$-actinin-positive CMs and transcript level of cardiac specific markers in beating EBs by inducing cell death of nonCMs. Baicalin increased the percentage of working ES-CMs which had typical responses to $\beta$-adrenergic and muscarinic stimulations. Conclusion: Baicalin maintains the late-stage functional CMs in EBs derived from murine ES cells. This study describes a new insight into the various biological effects of baicalin on cardiac differentiation of pluripotent stem cells.


Tang et al.: Baicalin and Cardiac Differentiation

\section{Introduction}

Ischemic heart disease is one of the leading causes of morbidity and mortality worldwide. Accumulated data have shown that cardiomyocytes (CMs) derived from embryonic stem (ES) cells (ES-CMs) have the potential to replenish the loss of myocardium that occurs in myocardial infarction and other cardiac diseases [1-4]. However, the spontaneous cardiac differentiation from ES cells is rather inefficient. This obviously limits the application of ES-CMs in cell replacement therapy. Therefore, it is necessary to develop a highly efficient system to produce sufficient numbers of functional ES-CMs.

Recently, many chemical inductors or cytokines such as 5-azacytidine [5], transforming growth factor- $\beta 1$ (TGF- $\beta 1$ ) [6] and hepatocyte growth factor [7] have been shown to selectively induce cardiac differentiation of ES cells. Although these compounds can support directed differentiation of ES cells to CMs, the efficiency is insufficient for therapeutic applications. Therefore, new ideas and economical methods to enhance the efficiency of cardiac differentiation are still needed.

Baicalin is a well-known cardiovascular protective agent that is isolated from a plant Scutellaria baicalensis [8-10]. It has been shown that baicalin promotes the in vitro hepatic differentiation of bone marrow-derived mesenchymal stem cells [11] and induces neuronal differentiation of stem cells $[12,13]$. However, whether baicalin has a role in the cardiac differentiation of pluripotent stem cells remains unknown.

In the present study, we investigated the effect of baicalin on the in vitro cardiac differentiation of murine ES cells. Our findings suggest that continuous application of baicalin maintains the late-stage functional CMs in embryoid bodies (EBs) derived from murine ES cells. This study describes a new insight into the various biological effects of baicalin on cardiac differentiation of pluripotent stem cells.

\section{Materials and Methods}

\section{Ethics Statement}

All animal work was conducted according to relevant national and international guidelines and was approved by Hubei Science and Technology Agency (2005-50).

\section{Cultivation of ES cells and cardiac differentiation}

The murine ES cell line D3 (CRL-1934, ATCC, USA) was maintained as previously described [14]. Briefly, ES cells were propagated on a confluent layer of mitomycin C-treated mouse embryonic fibroblasts (MEFs) in high glucose Dulbecco's modified Eagle's medium (DMEM), supplemented with 15\% fetal bovine serum (FBS), $2 \mathrm{mM}$ L-glutamine, 1\% nonessential amino acids, $100 \mathrm{U} / \mathrm{mL}$ penicillin, $100 \mu \mathrm{g} / \mathrm{mL}$ streptomycin, 0.1 mM $\beta$-mercaptoethanol and $1000 \mathrm{U} / \mathrm{mL}$ leukemia inhibitory factor (LIF, Chemicon, Temecula, USA). Cardiac differentiation was initiated by formation of EBs and removal of LIF as previously described [15-17]. Briefly, EBs were formed in hanging drops of 400 cells in $20 \mu \mathrm{l}$ of Iscoves's modified Dulbecco's medium (IMDM) containing 20\% FBS, and supplemented with the same additives as described above. After 2 days, the EBs were undergoing a 5-day suspension cultivation. The 7-day EBs were plated on gelatin-coated dishes for adherent cultivation until day 20.50 $\mu \mathrm{M}$ baicalin (Drug Biology Product Examination Bureau, China) was applied from the beginning of differentiation. Medium was changed every two days. Morphology and beating behavior of EBs were monitored by light microscopy with heating equipment at $37^{\circ} \mathrm{C}$. All cultivation medium and other substances for cell culture were purchased from Gibco BRL if not otherwise indicated.

The effect of baicalin on cardiac differentiation was also tested with the genetically modified D3 ES cell line $\alpha$ PIG (clone 44). CMs generated from this transgenic ES cells express puromycin resistance and green fluorescent protein (GFP) under control of the cardiac-specific promoter alpha-myosin heavy chain ( $\alpha$-MHC) [18]. Thus, ES-CMs will be GFP-positive enabling discrimination of ES-CMs from non-CMs in intact EBs. Transgenic ES cells were differentiated in a "mass culture" system [19]. Briefly, $1 \times 10^{6}$ ES cells were added in differentiation medium as described above and maintained on a shaker for two days. Then, 1000 EBs were added to $14 \mathrm{ml}$ of the fresh differentiation medium per $10 \mathrm{~cm}$ plate, and were kept on the shaker 


\begin{tabular}{lllc}
\hline Genes & Sense primers (5'-3') & \multicolumn{1}{c}{ Antisense primers (5'-3') } & $\begin{array}{c}\text { Product } \\
\text { size (bp) }\end{array}$ \\
\hline$\alpha$-MHC & GATTTCTCCAACCCAGCTGCGCC & CGGATGTCAAAGGGCCGGGTC & 201 \\
MLC-2v & TGTGGGTCACCTGAGGCTGTGGTTCAG & GAAGGCTGACTATGTCCGGGAGATGC & 189 \\
ANP & GCCGCACTTAGCTCCCTCCCCGAG & GTACCGGAAGCTGTTGCAGCCTAG & 241 \\
Nkx2.5 & CAAGTGCTCTCCTGCTTTCC & GGCTTTGTCCAGCTCCACT & 137 \\
Mef2c & GGCCATGGTACACCGAGTACAACGAGC & GGGGATCCCTGTGTTACCTGCACTTGG & 381 \\
Tbx5 & CACAGCCCCTTCAGCAGCGAGAC & AGGGGCCCCGAGGTGAAATGAG & 495 \\
GATA4 & TCTCACTATGGGCACAGCAG & GCGATGTCTGAGTGACAGGA & 136 \\
GAPDH & GTGTTCCTACCCCCAATGTG & CTTGCTCAGTGTCCTTGCTG & 349 \\
\hline
\end{tabular}

Table 1. Primers for RT-PCR and real-time PCR analysis

for further differentiation. Baicalin $(50 \mu \mathrm{M})$ was added at day 0 of differentiation and medium was changed every two days [19].

\section{Flow cytometry}

EBs at day 10, 16 and 20 of differentiation were washed twice in phosphate buffer saline (PBS) and dissociated into single cells by treatment with $0.05 \%$ trypsin/EDTA. For the detection of cardiac sarcomeric $\alpha$-actinin, the cells were fixed with $4 \%$ paraformaldehyde at room temperature for $20 \mathrm{~min}$. After permeabilization with $0.1 \%$ Triton X-100 in PBS on ice for $3 \mathrm{~min}, 1 \mathrm{ml}$ PBS was added and the cells centrifuged at $1500 \mathrm{rpm}$ for $5 \mathrm{~min}$. Cells were blocked with 1\% BSA in PBS and then incubated with the primary antibody at room temperature for $1 \mathrm{~h}$. After washing in PBS, the cells were incubated with the secondary antibody at room temperature for $1 \mathrm{~h}$. After washing in PBS, the cells were suspended in $400 \mu \mathrm{l}$ PBS and assayed by flow cytometry (FACS Calibur; Becton Dickinson, USA). Mouse IgG anti- $\alpha$-sarcomeric-actinin (A7811, 1:100, Sigma) served as the primary antibody. The secondary antibody was sheep anti-mouse R-Phycoerythrinconjugated IgG (P8547, 1:100, Sigma). Cells stained with primary isotype control antibody and secondary fluorescence-conjugated antibody served as a control. At least 10000 cells per sample were acquired. Cardiac differentiation was quantified by the percentage of $\alpha$-actinin-positive cells subtracted by negative control after gating out the dead cells. All of the data analyses were performed using the CellQuest software (Becton Dickinson).

\section{RT-PCR and real-time RT-PCR}

Total RNA was prepared from differentiated EBs using Trizol (Invitrogen) according to the instructions of the manufacturer. The total RNA $(2 \mu \mathrm{g})$ was reversely transcribed into cDNA using oligo (dT) primer and ReverTra Ace reverse transcriptase (Toyobo, Japan). For RT-PCR, $1 \mu \mathrm{l}$ of cDNA was used as the template. The cycling conditions consisted of an initial denaturing time of $5 \mathrm{~min}\left(\right.$ at $95^{\circ} \mathrm{C}$ ) followed by 29 cycles of denaturation at $95^{\circ} \mathrm{C}$ for $30 \mathrm{~s}$, annealing at (Tm-3) of each gene for $30 \mathrm{~s}$, and extension at $72^{\circ} \mathrm{C}$ for $45 \mathrm{~s}$, and a final extension at $72^{\circ} \mathrm{C}$ for $5 \mathrm{~min}$. The PCR products $(10 \mu \mathrm{l})$ were separated by agarose gel $(2 \%)$ electrophoresis, the density of the products was quantified using Image software version 1.38 (NIH Image). Glyceraldehyde-3-phosphate dehydrogenase (GAPDH) was used for the internal normalization. For each transcript, 3-5 independent experiments were analyzed.

Real-time PCR was performed in the Mx3000P real-time PCR system (Stratagene, USA) using SYBR Premix Ex Taq (TaKaRa, Japan). Amplification was performed with the following program cycle: step 1: $95^{\circ} \mathrm{C}$ for $30 \mathrm{~s}$; step 2: 40 cycles of $95^{\circ} \mathrm{C}$ for $5 \mathrm{~s}, 60^{\circ} \mathrm{C}$ for $20 \mathrm{~s}$, and finally ending with a melting curve acquisition. CT values were automatically obtained. Relative expression of mRNA amount was calculated using the $\Delta \Delta \mathrm{CT}$ method [20]. The primers used for RT-PCR and real-time PCR are listed in Table 1.

\section{LDH release Assay}

The cytotoxic effect of baicalin was assessed by the lactate dehydrogenase (LDH) release assay which was performed according to the instructions of the manufacturer (CytoTox-ONE ${ }^{\mathrm{TM}}$ Assay Kit, Promega, Germany). Briefly, after equilibrating at room temperature, $50 \mu \mathrm{l}$ of medium collected from baicalin-treated and control EBs and $50 \mu \mathrm{l}$ of CytoTox-ONE ${ }^{\mathrm{TM}}$ reagent (Promega, Germany) were added into each well of a black flat-bottom 96-well plate (Greiner, Germany), and incubated at room temperature for 10 min. Reactions 
Tang et al.: Baicalin and Cardiac Differentiation

were terminated by adding the stop solution, and the fluorescent signal was measured in the GENios Pro Microplate reader (TECAN, Switzerland) using filters with the excitation at $570 \mathrm{~nm}$ and emission at $612 \mathrm{~nm}$. Freshly prepared differentiation medium served as negative control.

\section{Detection of apoptotic cells in intact EBs}

Intact EBs of transgenic $\alpha$ PIG44 ES cells at day 14 were fixed in $4 \%$ paraformaldehyde at room temperature for $20 \mathrm{~min}$, washed with PBS and embedded in Tissue Tek OCT (Sakura Finetek Japan Co., Ltd., Tokyo). After cryoslicing ( $5 \mu \mathrm{m})$, cryosections were placed on silanized slides. The primary antibody antiactive caspase 3 (ab13847, 1:800, Abcam, UK) was visualized by anti-rabbit IgG1-Alexa Fluor 555 (A21430, 1:1000, Invitrogen, Germany). Nuclei were stained with Hoechst 33342 (Sigma-Aldrich, Germany). Stained EBs were imaged by using a Axiovert 200 fluorescence microscope and Axiovision 4.5 software (Carl Zeiss, Germany).

\section{Proliferation of purified ES-CMS}

Pure ES-CMs were generated from transgenic ES cell line $\alpha$ PIG44 by puromycin selection as described previously $[18,21]$. Puromycin $(8 \mu \mathrm{g} / \mathrm{mL}$, InvivoGen) was added at day 9 of differentiation and at day 12 or day 13 puromycin selected ES-CM clusters were collected and enzymatically dissociated into single cells using Trypsin/EDTA. $1 \times 10^{5}$ CMs were seeded per well of fibronectin-coated 48 -well plate and underwent further puromycin selection to avoid contamination of pluripotent stem cells with or without 50 $\mu \mathrm{M}$ baicalin. After $24 \mathrm{~h}$ of cultivation, the medium was changed to fresh medium with or without $50 \mu \mathrm{M}$ baicalin supplemented with $10 \mu \mathrm{M}$ EdU from the Click-iT® EdU Imaging Kit (Invitrogen, Germany). The cells were incubated for $24 \mathrm{~h}$ or $48 \mathrm{~h}$ under standard culture conditions. The cells were washed with PBS, fixed with 4\% paraformaldehyde for $15 \mathrm{~min}$ and permeabilized with $0.5 \%$ Triton X-100 in PBS for 20 min. The rabbit polyclonal anti-GFP antibody (A11122, 1:100, Invitrogen) was added and incubated for $16 \mathrm{~h}$ at $4^{\circ} \mathrm{C}$. The secondary goat anti-rabbit IgG 647 (A21244, 1:200, Invitrogen) was added for $1 \mathrm{~h}$ at room temperature. Cells were washed twice with 3\% BSA in PBS and the EdU staining was performed according to the manufacturer's instructions. Nuclei were stained with Hoechst 33342. Finally the cells were washed with MilliQ water and coated with $0.5 \%$ DAPCO in 50\% glycerol. Images were taken from randomly chosen fields by using the Axiovert 200 fluorescence microscope and Axiovision 4.5 software. The number of proliferating CMs was determined by analyzing the randomly taken images. The percentage of proliferating CMs was determined by dividing the number of EdU and GFP double positive cells by the total number of GFP-positive CMs. The counting was performed independently by three operators.

\section{Proliferation assay of the embryonic ventricular CMS}

Pregnant mice (Kunming mice provided by the Center of Animal Experimentation of Tongji Medical College, Huazhong University of Science and Technology, China) were sacrificed at E16.5 post coitum and the embryos were removed. The ventricles of the embryonic hearts were dissected and enzymatically dissociated into single cells as described earlier [22]. $4 \times 10^{4}$ cells per well were seeded in a gelatin-coated 24-well-plate. The cells were used for the proliferation assay $24 \mathrm{~h}$ after plating by employing the Cell-Light ${ }^{\mathrm{TM}}$ EdU Apollo®567 In Vitro Flow Cytometry Kit (RIBOBIO, Guangzhou, China). Embryonic CMs were identified by staining with mouse IgG anti- $\alpha$-sarcomeric-actinin antibody (A7811, 1:200, Sigma-Aldrich) overnight at $4^{\circ} \mathrm{C}$. The secondary goat anti-mouse FITC-conjugated IgG (SA00003-1, 1:100, Proteintech) was added for 1 $\mathrm{h}$ at room temperature. Cells were washed with PBS and the EdU staining was performed. Nuclei were stained with DAPI ( $1 \mu \mathrm{g} / \mathrm{mL}$, Sigma-Aldrich). Images were randomly taken by using fluorescence microscope (Nikon, TE2000-S, Japan). The total number of CMs was determined by counting $\alpha$-actinin/DAPI double positive cells. The number of proliferating CMs was determined by counting the $\alpha$-actinin/EdU/DAPI triple positive cells.

\section{Electrophysiological recordings}

The action potentials (APs) were recorded from spontaneously beating ES-CMs using the whole-cell patch-clamp under current-clamp mode [23]. A coverslip with adhered cells was placed in a temperaturecontrolled $\left(37 \pm 0.3^{\circ} \mathrm{C}\right)$ recording chamber which was mounted on the stage of an inverted microscope (Zeiss, Germany), and continuously superfused with normal Tyrode's solution consisting of the following components (mM): $\mathrm{NaCl}, 140 ; \mathrm{KCl}, 5.4 ; \mathrm{CaCl}_{2}, 1.8 ; \mathrm{MgCl}_{2}, 1 ; \mathrm{HEPES}, 10$; and glucose, 10 (pH adjusted to 7.2- 
Tang et al.: Baicalin and Cardiac Differentiation

7.4 with $\mathrm{NaOH}$ ). Patch pipettes ( 2 to $5 \mathrm{M} \Omega$ ) were filled with the internal solution consisting of the following components (mM): KCl, 50; K-aspartate, 80; $\mathrm{MgCl}_{2}, 1$; $\mathrm{Na}_{2} \mathrm{ATP}, 3$; EGTA, 10; and HEPES, 10 (pH adjusted to 7.2-7.4 with $\mathrm{KOH}$ ). Signals acquired from the ES-CMs were magnified by an Axopatch 200A amplifier (Axon Instruments, CA, USA) at a sampling rate of $10 \mathrm{kHz}$, filtered at $2 \mathrm{kHz}$, stored on a computer and analyzed using Clampfit 9.0 and AP For Lym software. The APs were classified using previously described criteria. Isoproterenol (Iso, $1 \mu \mathrm{M}$; Sigma) or carbachol (Cch, $1 \mu \mathrm{M}$; Sigma) was added to the Tyrode's solution to detect the adrenergic and muscarinic regulation of CMs.

\section{Statistical analysis}

Data are expressed as mean \pm SEM for at least three independent experiments. Statistical significance was evaluated using paired or unpaired $t$ test where appropriate, $p<0.05$ was considered as statistically significant.

\section{Results}

Baicalin increases the proportion of CMs in EBs derived from ES cells

The onset of spontaneous beating was observed at day 8, and the percentage of beating EBs increased gradually and reached the peak at day 13 in both groups (Fig. 1A). There were no significant differences between the groups until day 16. From day 16 to day 20 the percentage of beating EBs remained at the same level as on day 13 in the baicalin group but was gradually decreased in the control group $(p<0.05, \mathrm{n}=5)$. At day $20,85.2 \% \pm 7.4 \%$ of the EBs treated with baicalin exhibited spontaneous beating compared to $11.2 \% \pm 2.2 \%$ in the control group. These results indicate that baicalin prevents loss of ES-CMs in the EBs at later differentiation stages.

We next studied the effect of baicalin on the expression levels of cardiac transcription factors and cardiac specific genes by RT-PCR and real-time PCR. Transcripts of the cardiac transcription factor NK 2 transcription factor related locus 5 ( $\mathrm{Nkx} 2.5)$ were elevated by baicalin at day 20 (Fig. 1B and C). The other cardiac transcription factor GATA binding protein 4 (GATA4), T-box 5 (Tbx5) and myocyte enhancer factor 2c (Mef2c) showed no remarkable differences in transcript abundance between baicalin and control variants (Fig. 1B). Cardiac specific genes $\alpha$-myosin heavy chain $(\alpha-M H C)$, myosin light chain- $2 \mathrm{v}($ MLC- $2 \mathrm{v}$ ) and atrial natriuretic peptide (ANP) were up-regulated at differentiation day 16 and 20 in baicalin treated EBs (Fig. 1B and C). In addition, flow cytometric quantification of the proportion of $\alpha$-actinin-positive cells revealed that the percentage of $\alpha$-actinin-positive cells was significantly higher in baicalin group (38.4 $\pm 4.7 \%)$ than control group $(28.5 \pm 5.2 \%)(p<0.05, \mathrm{n}=$ 5 ) at day 20 (Fig. 1D, E). These data suggest that baicalin increases the relative percentage of ES-CMs at the late stage but does not affect early cardiac differentiation.

\section{CMs derived from baicalin-treated ES cells are electrophysiological intact}

We next investigated the electrophysiological properties of baicalin induced ES-CMs by patch-clamp. The APs were classified by the criteria described previously [24-26]. Typical pacemaker-like, atrial-like and ventricular-like APs were recorded in both groups (Fig. 2A). Interestingly, we found that baicalin increased the percentage of ventricular-like and atriallike working myocardium cells while decreased that of pacemaker-like cells (Fig. 2B and Table 2). These ES-CMs had well established $\beta$-adrenergic receptor and muscarinic acetylcholine receptor signaling pathways, as indicated by typical responses to Iso $(1 \mu \mathrm{M})$ (Fig. 2C) and Cch $(1 \mu \mathrm{M})$ (Fig. 2D). These responses showed no significant differences in the baicalin treated and control cells (Fig. 2E). The parameters of AP such as maximal diastolic potential (MDP), AP amplitude (APA) and AP duration measured from the maximal depolarization to $90 \%$ repolarization (APD90) were not significantly affected by baicalin treatment (Table 2). These data demonstrate that CMs derived from baicalin-treated ES cells are electrophysiological intact. 


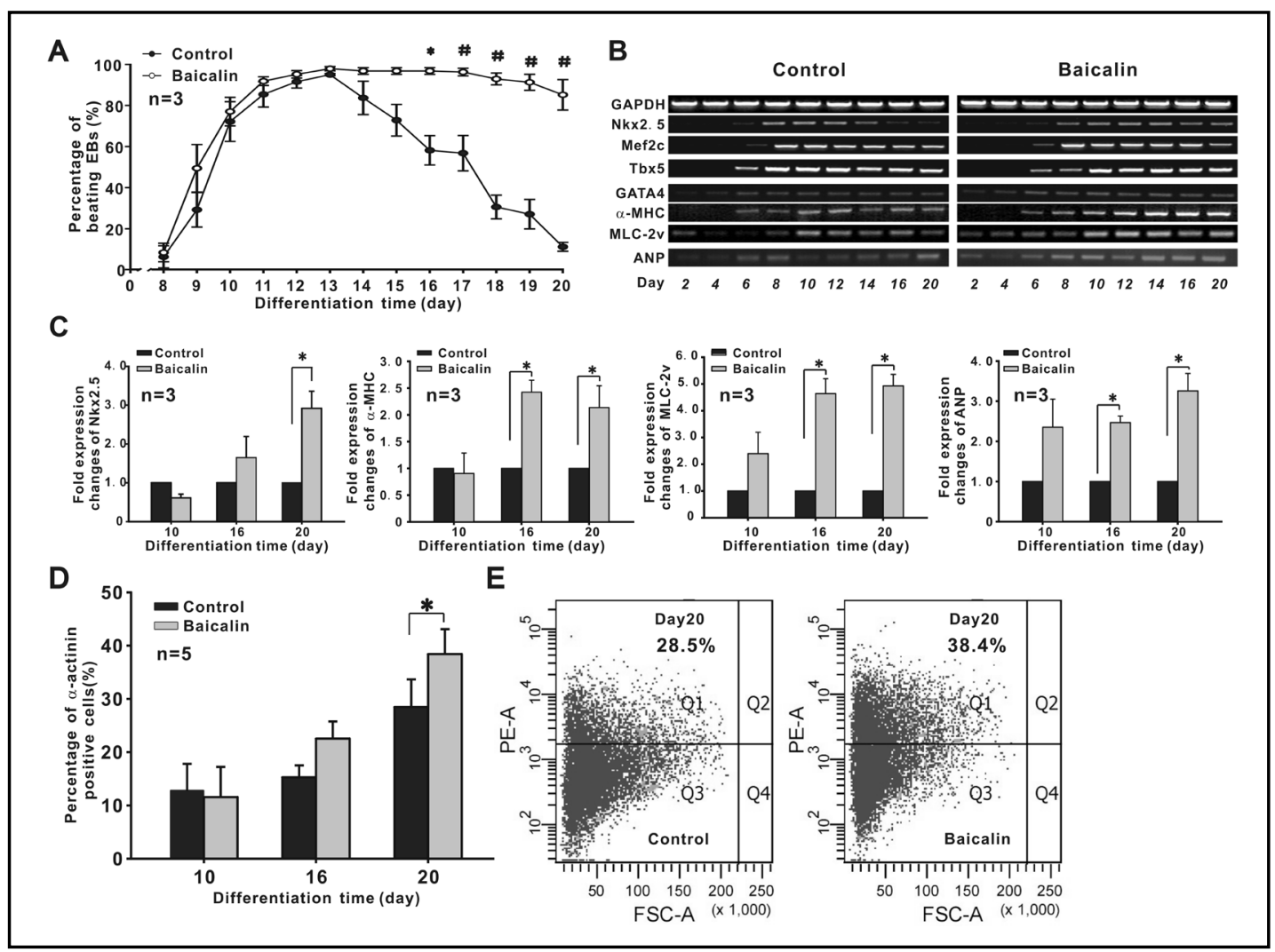

Fig. 1. Baicalin increases the proportion of CMs in EBs derived from ES cells. (A) Percentage of beating EBs during differentiation. $\mathrm{n}=3 .{ }^{*}, p<0.05$. \#, $p<0.01$. (B) RT-PCR analysis and (C) Real-time PCR analysis of the mRNA levels of indicated cardiac transcription factors and cardiac markers in the EBs during differentiation. The data are showed as mean \pm SEM, $n=3$ independent experiments. ${ }^{*}, p<0.05$. (D) Flow cytometric analysis shows the percentage of $\alpha$-actinin-positive cells in the total population of cells of EBs derived from the ES cells at different stages of differentiation $(n=5)$. Data are presented as mean \pm SEM. $*, p<0.05 v s$. control. (E) The representative data of flow cytometric analysis at day 20 of differentiation. $\alpha$-actinin-positive cells are shown in quadrant 1 (Q1).

\section{Baicalin decreases the size of EBs by inducing cell death in EBs prior to appearance of beating}

In order to determine if the kinetics of EB growth is affected by baicalin, we determined the diameter of EBs grown in suspension in baicalin treated and untreated group. The average diameters of EBs in baicalin group were significantly decreased at all observation time points (Fig. 3A). The maximal EB diameter was reached at day 11 of differentiation in control group $(2.20 \pm 0.05 \mathrm{~mm}, \mathrm{n}=90)$, and at day 9 of differentiation in the baicalin group (1.53 \pm $0.03 \mathrm{~mm}, \mathrm{n}=90)$.

To determine whether the reduction of EB size is due to cytotoxic effect of baicalin, we measured the concentration of the LDH released by dead cells in the medium of baicalin treated and control EBs. At day 2 of differentiation, similar amount of LDH was detected in the medium of both groups. However, at day 4 of differentiation baicalin treated EBs released 11-fold more LDH into the medium than control EBs. At day 6 the LDH release in baicalin group declined compared to day 4 but was still significantly higher (2.5-fold) than in control group (Fig. 3B). In the following days the LDH release in baicalin group gradually decreased below the values obtained at day 2. Interestingly, the LDH release in the control group increased and became significantly higher than that of the baicalin group at day 12 and 14 of differentiation, possibly due to increased cell death caused by insufficient nutrient supply in large EBs. 


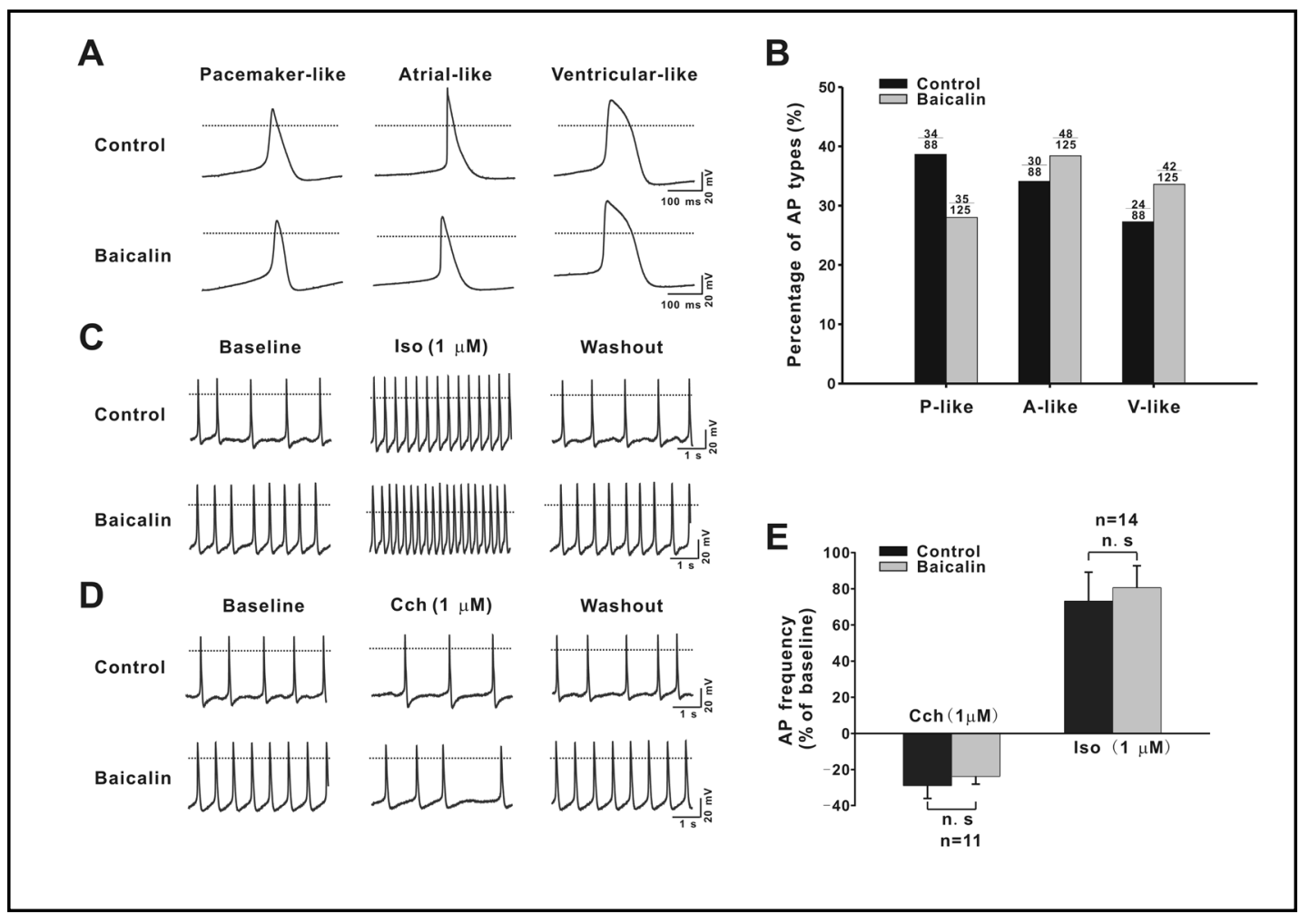

Fig. 2. Electrophysiological characterization of ES-CMs using patch-clamp. (A) Three major types of APs were discriminated in the baicalin treatment and control mES-CMs: pacemaker-like, atrial-like and ventricular-like APs. (B) The relative percentage of the AP types recorded from the control and baicalin treatment cultures. P-like, pacemaker-like AP; A-like, atrial-like AP; V-like, ventricular-like AP. Data were acquired from 88 control mES-CMs and 125 baicalin treatment mES-CMs of 4 independent differentiations. (C) Application of isoproterenol (Iso, $1 \mu \mathrm{M}$ ) resulted in an increase of the AP frequency. (D) Application of carbachol (Cch, $1 \mu \mathrm{M}$ ) resulted in an decrease of the AP frequency. (E) The effects of Cch and Iso on AP frequency changes in the baicalin treatment and control murine ES-CMs. n.s, non-significant difference between control and baicalin treatment groups.

\begin{tabular}{lllll}
\hline & $\mathrm{n}(\mathrm{cell})$ & MDP $(\mathrm{mV})$ & APA (mV) & APD90 (ms) \\
\hline Control & 88 & & & \\
Pacemaker-like & $34(38.6 \%)$ & $-55.8 \pm 0.7$ & $67.7 \pm 1.5$ & $88.0 \pm 3.0$ \\
Atrial-like & $30(34.1 \%)$ & $-57.9 \pm 0.6$ & $76.4 \pm 1.6$ & $87.1 \pm 3.6$ \\
Ventricular-like & $24(27.3 \%)$ & $-59.4 \pm 0.9$ & $82.0 \pm 2.5$ & $102.3 \pm 6.2$ \\
Baicalin & 125 & & & \\
Pacemaker-like & $35(28.0 \%)$ & $-54.7 \pm 0.6$ & $71.2 \pm 1.7$ & $79.7 \pm 4.0$ \\
Atrial-like & $48(38.4 \%)$ & $-56.5 \pm 0.7$ & $77.2 \pm 1.6$ & $80.0 \pm 3.2$ \\
Ventricular-like & $42(33.6 \%)$ & $-57.3 \pm 0.7$ & $85.9 \pm 1.8$ & $92.0 \pm 4.6$
\end{tabular}

Table 2. Action potential properties of murine ES-CMs. Data were presented as the mean \pm SEM. $n$ indicates the number of cells tested from 4 independent differentiations. There was no significant difference between MDP, APA and APD90 in control and baicalin treatment group. AP, action potentials; MDP, maximal diastolic potential; APA, AP amplitude; APD90, AP duration measured from the maximal depolarization to $90 \%$ repolarization in ms.

In order to assess whether the cytotoxic effect of baicalin is limited only to non-CMs, we performed the immunohistological stainings for active caspase 3 in sections of intact EBs at 
A

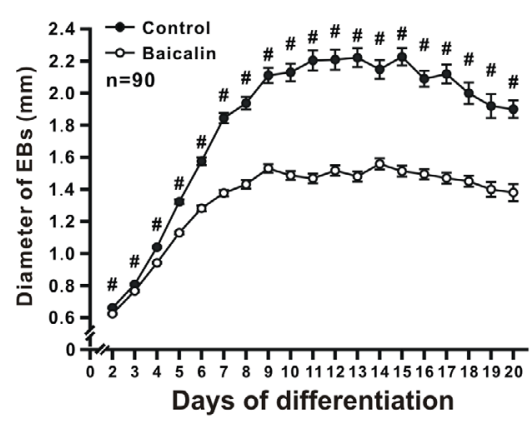

C
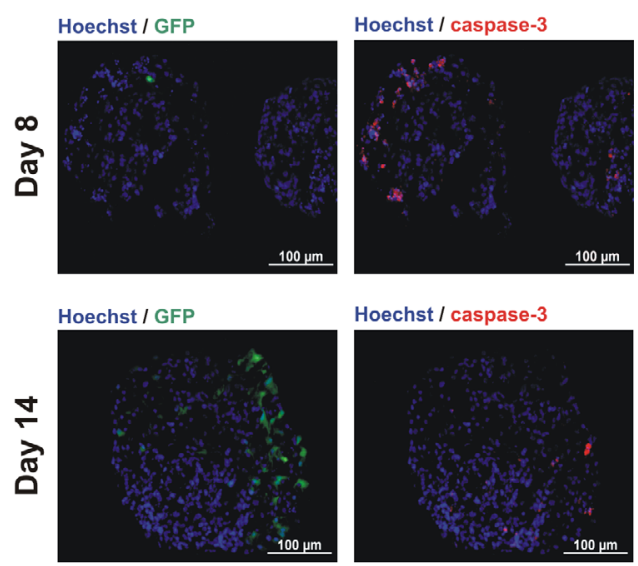

Hoechst / caspase-3

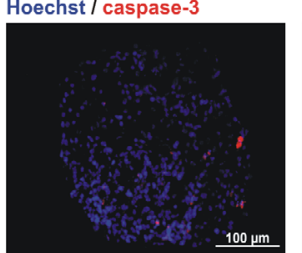

B
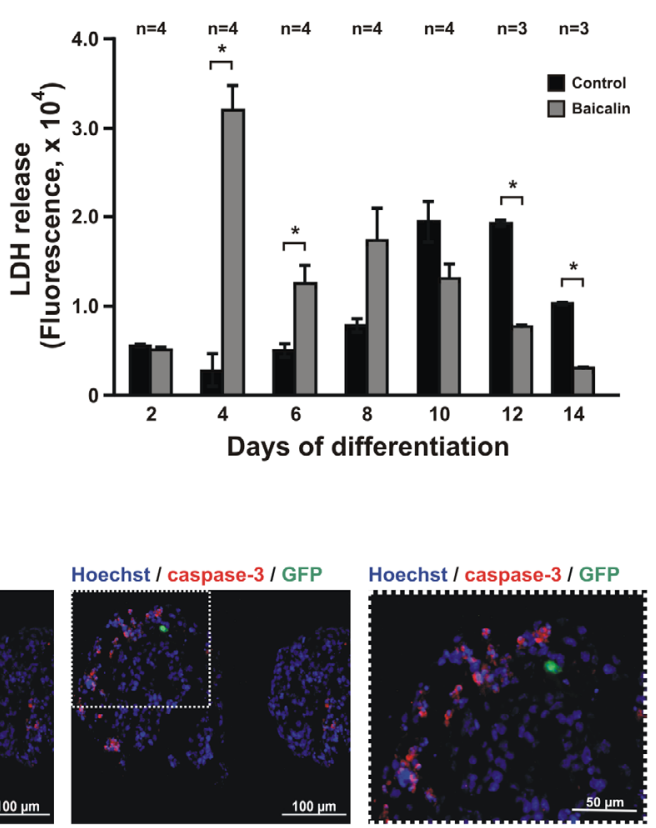

Hoechst / caspase-3 / GFP

Hoechst / caspase-3 / GFP

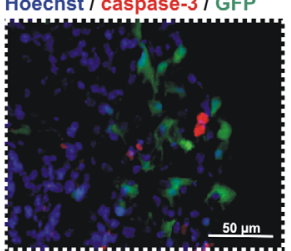

Fig. 3. Baicalin decreases the size of EBs by inducing cell death of non-CMs in initial stages of differentiation (day 4-8). (A) Changes of the diameter of the differentiating EBs with or without baicalin treatment. Data are expressed as mean \pm SEM. $n=90$ EBs from three independent differentiations for each time point. \#, $p<$ 0.01. (B) The time-course of LDH release into the medium of differentiating EBs. Note that LDH release was markedly elevated in baicalin group in early stages of differentiation (day 4-8). Data are expressed as mean \pm SEM. $\mathrm{n}=3$ or 4 . $^{*}, p<0.05$. (C) Staining of active caspase 3 in the cryosections of 8-days-old (upper panels) and 14-days-old (lower panels) baicalin treated EBs. Note that GFP-positive CMs were not positive for active caspase 3. Red, active caspase 3; Green, native GFP in CMs; Blue, Hoechst 33342. Scale bar $=100 \mu \mathrm{m}$.

day 8 and 14 of differentiation from baicalin group. These analyses showed that all caspase 3-positive cells were GFP-negative non-CMs (Fig. 3C), indicating that long-term baicalin treatment did not induce apoptosis of ES-CMs in differentiating EBs. These results indicate that baicalin decreases the size of EBs by inducing the death of non-CMs in initial stages (day 4-8) of ES cell differentiation.

\section{Baicalin does not affect the proliferation and viability of CMS}

CM proliferation is one of the most important physiological steps in heart development, which is regulated by a number of cytokines and growth factors [27]. Therefore, to determine whether baicalin-induced increase in the proportion of CMs in EBs is mediated by stimulation of CM proliferation, proliferation of purified CMs differentiated from the transgenic ES cells line $\alpha$ PIG44 and ventricular CMs obtained from E16.5 embryonic hearts was measured using the EdU incorporation assay. These analyses revealed that cultivation in the presence of $50 \mu \mathrm{M}$ baicalin for $24 \mathrm{~h}$ or $48 \mathrm{~h}$ did not affect the proliferation of purified ES-CMs (Fig. 4A and B). Similarly, baicalin also neither stimulated nor reduced the proliferation of embryonic ventricular CMs (Fig. 4C and D). Comparison of ES-CMs incubated under control and 
A
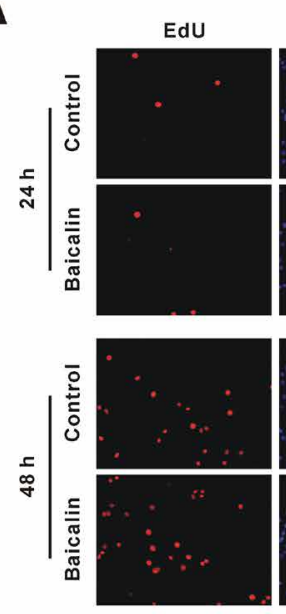

C

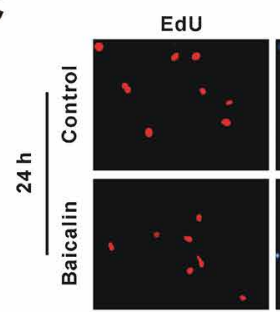

Hoechst
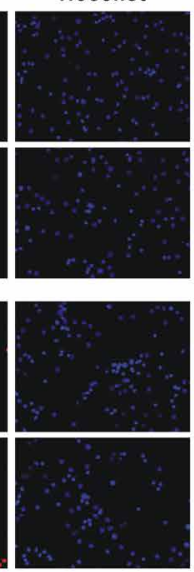

DAPI

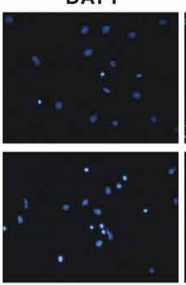

GFP
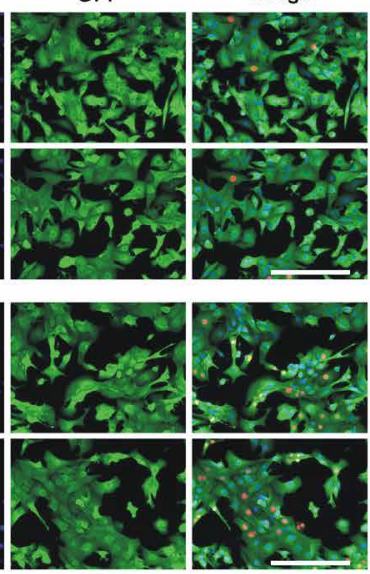

$\alpha$-actinin

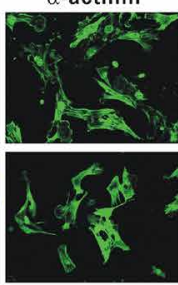

Merge

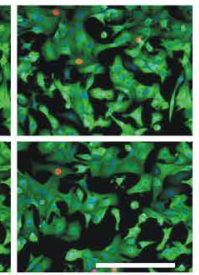

Merge

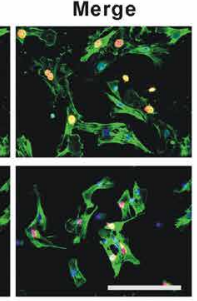

B
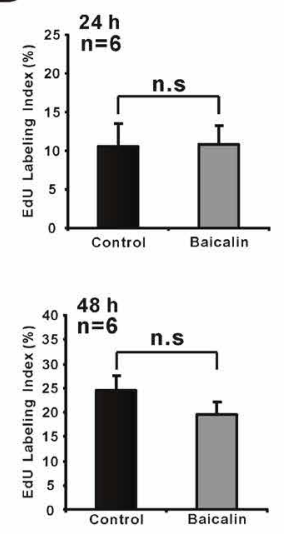

D

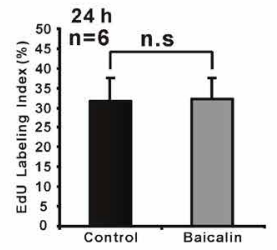

Fig. 4. Baicalin does not affect the proliferation and viability of CMs. (A) The representative images showing proliferating cells (EdU-positive nuclei, red) in cultures of purified GFP-positive CMs (green) derived from a transgenic ES cell line $\alpha$ PIG44. Nuclei were counterstained with Hoechst 33342 (blue). CMs were obtained by puromycin selection for 3-4 days and at day 12 or 13 of differentiation cardiac clusters were dissociated by trypsinization and plated. Adherent CMs were incubated with EdU for $24 \mathrm{~h}$ (upper panels) or $48 \mathrm{~h}$ (lower panels) in the presence or absence of $50 \mu \mathrm{M}$ baicalin. (B) The quantitation of the EdU proliferation assay from A. The EdU labeling index was defined as the ratio of GFP/EdU labelled cells to total number of GFPpositive cells. (C) The representative staining for $\alpha$-actinin (green) and EdU (red), in cultured CMs isolated from embryonic ventricle at E16.5. (D) The statistical evaluation of the proliferation assay with embryonic CMs from D. The EdU labeling index was defined as the ratio of $\alpha$-actinin/EdU labelled cells to the total number of $\alpha$-actinin-positive cells. Scale bar $=200 \mu \mathrm{m} . \mathrm{n}=6$. n.s, non-significant difference between control and baicalin treatment groups.

baicalin treated conditions revealed that CMs in both groups possessed normal morphology, indicating that baicalin did not affect the viability of ES-CMs, further confirming the data obtained by assessing the active caspase 3-positive cells in intact EBs (see Fig. 3C above). These findings indicate that baicalin increases the ratio between CMs and non-CMs in intact EBs by eliminating non-CMs and preserving the viability of CMs, but not by affecting their proliferation.

\section{Discussion}

The root of Scutellaria baicalensis has been used clinically in Chinese medicine for thousands of years [28]. Baicalin is the major constituent of Scutellaria baicalensis, which is a well-known cardiovascular protective agent. Baicalin possesses anti-oxidant and antiinflammatory activities, and thus can protect CMs exposed to ischemia/reperfusion [10, 29]. However, whether baicalin affects the cardiac differentiation is still not known. 
Key findings of the present study are: (1) baicalin maintains the late-stage ES-CMs which express typical cardiac markers and are electrophysiological intact, but does not affect early cardiac differentiation; (2) continuous exposure of ES cells to baicalin induces cell death of non-CMs but not of CMs in EBs derived from ES cells; (3) baicalin decreases the proportion of pacemaker-like cells, whereas increases that of atrial-like and ventricular-like cells.

Murine pluripotent stem cells yield a heterogeneous population of CMs [16, 30]. Ventricular myocytes and atrial myocytes are morphologically, molecularly, and functionally distinct from pacemaker cells [31]. Until now, the molecular mechanisms of the formation of the four-chambered mammalian heart are still not fully known. Many transcription factors and structural genes cooperate and interact with each other to precisely control the development and the formation of the chambered heart [31]. Here we found that baicalin up-regulates the Nkx2.5, MLC-2v and ANP at the intermediate and late stages of differentiation. Nkx2.5 is a transcription factor which is important for the differentiation of chamber myocardium [32]. Nkx2.5-deficient mice display normal cardiogenesis but fail to form heart chambers $[33,34]$. The expression of MLC-2v is widely used to demarcate ventricular-like CMs [35]. Moreover, ANP was suggested to be used as a marker for differentiation of the working myocardial cells rather than a marker of atrial-like cells in ES cell cultures [35]. It was found that Nkx2.5 interacts physically with GATA4 and acts synergistically to activate the ANP promoter [36,37]. It was also reported that the expression of ANP is mediated through binding of Nkx2.5 and GATA4/GATA6 on the NKE and GATA sites, respectively [38]. Nkx2.5 and dHAND cooperatively regulated the expression of ventricular specific Iroquois homeobox gene 4 (IRX4) was reported [39]. Therefore, baicalin-induced up-regulation of Nkx2.5 might account for the increase of atrial-like and ventricular-like cells. To address the underlying mechanism, further studies are needed.

The increased proportion of working CMs might be related to: (1) a promoted cardiac differentiation; (2) an enhanced CMs proliferation; (3) and/or a decreased total cell population in differentiating ES cells.

It has been shown that multiple signaling events are involved in cardiogenesis of ES cells, including TGF- $\beta$ [40], BMP [41] and Wnt signaling pathways $[42,43]$ TGF- $\beta$ is expressed in differentiating ES cells. A recent report showed that TGF- $\beta$ signaling plays a biphasic role in ES cells cardiogenesis [44]. It promotes mesoderm induction and subsequently inhibits cardiac differentiation specifically. Wnt/ $\beta$-catenin signaling exerts multiple cellular effects such as increasing cell viability, cell proliferation, and cardiomyogenesis in mouse $[42,45]$ and human ES cells [43]. However, manipulation of Wht signaling during ES cell differentiation can either hinder or enhance cardiac differentiation, often leading to apparently conflicting effects. In the present study, we tested the effects of baicalin on all these signaling pathways. Unfortunately, we did not find that baicalin affect the transcript level of TGF- $\beta 1 / 2 / 3$, Wnt and BMP4 from day 0 up to day 16 of differentiation (data not shown). This indicated that baicalin might not interfere with these signaling pathways during differentiation, and therefore the cardiac differentiation was maintained in the present of baicalin.

We found that baicalin induces cell death in the differentiating ES cells at the initial stage of differentiation, which might account for the smaller EB size and the increased percentage of ES-CMs in the remaining cells. At the same time we could show that baicalin treatment maintains a higher percentage of beating CMs at the late stage of ES cell differentiation. Several groups reported that baicalin induced apoptosis of cancer cells [46] and carcinoma cells [47], via ERK and p38 MAPK signaling pathways. However, baicalin also showed cytoprotective effects on CMs [48, 49], hepatocytes and neural cells [50-52]. A latest study reported that baicalin attenuates acute myocardial infarction of rats via mediating ERK and p38 MAPK signaling pathways [48]. In this latest study, baicalin treatment significantly augments the phosphorylated ERK (p-ERK) while dramatically diminishes the phosphorylated JNK (p-JNK) and p38 (p-p38) in rats with myocardial infarction [48]. Therefore, we propose that baicalin selectively induces the death of specific cell types but not CMs in EBs during differentiation, giving rise to smaller EBs with relative higher proportion of ES-CMs. We also hypothesize that other anti-cancer drugs might have similar effects on cardiac differenti- 
Tang et al.: Baicalin and Cardiac Differentiation

ation. Further works are suggested to better understand the new biological effect of anticancer agents.

A recent study reported that baicalin stimulates the expression of vascular endothelial growth factor (VEGF) in human fibroblasts, human umbilical endothelial cells and human glioma cells under hypoxia or normoxia culture condition and induces microvessel sprouting and angiogenesis in chick aortic arch [53]. Angiogenesis is important for the survival of the transplanted ES-CMs in infarcted area of the heart. Therefore, considering all the previous reports and our findings, we suggest that application of baicalin might be good for cell transplantation to restore the mechanical function after myocardium infarction.

This study provides the first report of the effect of baicalin on the cardiac differentiation of ES cells. Our data demonstrate that baicalin can successfully maintain cardiac differentiation and relatively increase the production of functional working ES-CMs. However, in contrast to other reported chemical compounds [16, 54], baicalin did not accelerate early cardiac differentiation of ES cells. Additional work is needed to define the optimal time frame for the maximal effect of baicalin on cardiogenesis and to further confirm its effects on human pluripotent stem cells.

\section{Conflict of Interest}

The authors declare no competing financial interests.

\section{Acknowledgments}

This study was supported by the National Natural Science Foundation of China (No.31100828 and No.30700262), the Natural Science Foundation of Hubei Province (2011CDB363), the Project-sponsored by SRF for ROCS Jiaoya Xi, SEM, the Fundamental Research Funds for the Central Universities (HUST:2011QN211 and 2013TS145), the Science Foundation of HUST for Jiaoya Xi, and the Ph.D Program Foundation of SEM (20070487012) for Ming Tang, the German Ministry for Education and Research (Bundesministerium für Bildung und Forschung, BMBF) to Tomo Šarić, Markus Khalil and Jürgen Hescheler (No.01GN0947 and No.01GN0937) and the European Union to Jürgen Hescheler (project "Infarct Cell Therapy").

\section{References}

1 Mummery C, Ward D, van den Brink CE, Bird SD, Doevendans PA, Opthof T, Brutel de la Riviere A, Tertoolen L, van der Heyden M, Pera M: Cardiomyocyte differentiation of mouse and human embryonic stem cells. J Anat 2002;200:233-242.

-2 Caspi O, Huber I, Kehat I, Habib M, Arbel G, Gepstein A, Yankelson L, Aronson D, Beyar R, Gepstein L: Transplantation of human embryonic stem cell-derived cardiomyocytes improves myocardial performance in infarcted rat hearts. J Am Coll Cardiol 2007;50:1884-1893.

-3 Laflamme MA, Chen KY, Naumova AV, Muskheli V, Fugate JA, Dupras SK, Reinecke H, Xu C, Hassanipour M, Police S, O'Sullivan C, Collins L, Chen Y, Minami E, Gill EA, Ueno S, Yuan C, Gold J, Murry CE: Cardiomyocytes derived from human embryonic stem cells in pro-survival factors enhance function of infarcted rat hearts. Nat Biotechnol 2007;25:1015-1024.

-4 van Laake LW, Passier R, Monshouwer-Kloots J, Verkleij AJ, Lips DJ, Freund C, den Ouden K, Ward-van Oostwaard D, Korving J, Tertoolen LG, van Echteld CJ, Doevendans PA, Mummery CL: Human embryonic stem cell-derived cardiomyocytes survive and mature in the mouse heart and transiently improve function after myocardial infarction. Stem Cell Res 2007;1:9-24. 
Tang et al.: Baicalin and Cardiac Differentiation

5 Yoon BS, Yoo SJ, Lee JE, You S, Lee HT, Yoon HS: Enhanced differentiation of human embryonic stem cells into cardiomyocytes by combining hanging drop culture and 5-azacytidine treatment. Differentiation 2006;74:149-159.

6 Schuldiner M, Yanuka O, Itskovitz-Eldor J, Melton DA, Benvenisty N: Effects of eight growth factors on the differentiation of cells derived from human embryonic stem cells. Proc Natl Acad Sci U S A 2000;97:1130711312.

7 Roggia C, Ukena C, Bohm M, Kilter H: Hepatocyte growth factor (HGF) enhances cardiac commitment of differentiating embryonic stem cells by activating PI3 kinase. Exp Cell Res 2007;313:921-930.

$\rightarrow 8$ Shieh DE, Liu LT, Lin CC: Antioxidant and free radical scavenging effects of baicalein, baicalin and wogonin. Anticancer Res 2000;20:2861-2865.

-9 Chan FL, Choi HL, Chen ZY, Chan PS, Huang Y: Induction of apoptosis in prostate cancer cell lines by a flavonoid, baicalin. Cancer Lett 2000;160:219-228.

10 Chang WT, Shao ZH, Yin JJ, Mehendale S, Wang CZ, Qin Y, Li J, Chen WJ, Chien CT, Becker LB, Vanden Hoek TL, Yuan CS: Comparative effects of flavonoids on oxidant scavenging and ischemia-reperfusion injury in cardiomyocytes. Eur J Pharmacol 2007;566:58-66.

11 Qiao H, Tong Y, Han H, Xu W, Ren Z, Ouyang J, Chen Y: A novel therapeutic regimen for hepatic fibrosis using the combination of mesenchymal stem cells and baicalin. Pharmazie 2011;66:37-43.

12 Yan XH, Huang RB: [Differentiation of human umbilical cord blood mesenchymal stem cells toward neurons induced by baicalin in vitro]. Zhonghua Er Ke Za Zhi 2006;44:214-219.

13 Li M, Tsang KS, Choi ST, Li K, Shaw PC, Lau KF: Neuronal differentiation of C17.2 neural stem cells induced by a natural flavonoid, baicalin. Chembiochem 2011;12:449-456.

14 Sauer H, Rahimi G, Hescheler J, Wartenberg M: Effects of electrical fields on cardiomyocyte differentiation of embryonic stem cells. J Cell Biochem 1999;75:710-723.

15 Takahashi T, Lord B, Schulze PC, Fryer RM, Sarang SS, Gullans SR, Lee RT: Ascorbic acid enhances differentiation of embryonic stem cells into cardiac myocytes. Circulation 2003;107:1912-1916.

16 Wobus AM, Kaomei G, Shan J, Wellner MC, Rohwedel J, Ji G, Fleischmann B, Katus HA, Hescheler J, Franz WM: Retinoic acid accelerates embryonic stem cell-derived cardiac differentiation and enhances development of ventricular cardiomyocytes. J Mol Cell Cardiol 1997;29:1525-1539.

$\checkmark 17$ Wobus AM, Guan K, Yang HT, Boheler KR: Embryonic stem cells as a model to study cardiac, skeletal muscle, and vascular smooth muscle cell differentiation. Methods Mol Biol 2002;185:127-156.

18 Kolossov E, Bostani T, Roell W, Breitbach M, Pillekamp F, Nygren JM, Sasse P, Rubenchik O, Fries JW, Wenzel D, Geisen C, Xia Y, Lu Z, Duan Y, Kettenhofen R, Jovinge S, Bloch W, Bohlen H, Welz A, Hescheler J, Jacobsen SE, Fleischmann BK: Engraftment of engineered ES cell-derived cardiomyocytes but not BM cells restores contractile function to the infarcted myocardium. J Exp Med 2006;203:2315-2327.

19 Xi J, Khalil M, Spitkovsky D, Hannes T, Pfannkuche K, Bloch W, Saric T, Brockmeier K, Hescheler J, Pillekamp F: Fibroblasts support functional integration of purified embryonic stem cell-derived cardiomyocytes into avital myocardial tissue. Stem Cells Dev 2011;20:821-830.

20 Winer J, Jung CK, Shackel I, Williams PM: Development and validation of real-time quantitative reverse transcriptase-polymerase chain reaction for monitoring gene expression in cardiac myocytes in vitro. Anal Biochem 1999;270:41-49.

-21 Frenzel LP, Abdullah Z, Kriegeskorte AK, Dieterich R, Lange N, Busch DH, Kronke M, Utermohlen O, Hescheler J, Saric T: Role of natural-killer group 2 member D ligands and intercellular adhesion molecule 1 in natural killer cell-mediated lysis of murine embryonic stem cells and embryonic stem cell-derived cardiomyocytes. Stem Cells 2009;27:307-316.

-22 Liu A, Tang M, Xi J, Gao L, Zheng Y, Luo H, Hu X, Zhao F, Reppel M, Hescheler J, Liang H: Functional characterization of inward rectifier potassium ion channel in murine fetal ventricular cardiomyocytes. Cell Physiol Biochem 2010;26:413-420.

23 Maltsev VA, Wobus AM, Rohwedel J, Bader M, Hescheler J: Cardiomyocytes differentiated in vitro from embryonic stem cells developmentally express cardiac-specific genes and ionic currents. Circ Res 1994; 75:233-244.

-24 Fassler R, Rohwedel J, Maltsev V, Bloch W, Lentini S, Guan K, Gullberg D, Hescheler J, Addicks K, Wobus AM: Differentiation and integrity of cardiac muscle cells are impaired in the absence of beta 1 integrin. J Cell Sci 1996;109:2989-2999. 
Tang et al.: Baicalin and Cardiac Differentiation

25 Maltsev VA, Rohwedel J, Hescheler J, Wobus AM: Embryonic stem cells differentiate in vitro into cardiomyocytes representing sinusnodal, atrial and ventricular cell types. Mech Dev 1993;44:41-50.

-26 Zhang Q, Jiang J, Han P, Yuan Q Zhang J, Zhang X, Xu Y, Cao H, Meng Q, Chen L, Tian T, Wang X, Li P, Hescheler J, Ji G, Ma Y: Direct differentiation of atrial and ventricular myocytes from human embryonic stem cells by alternating retinoid signals. Cell Res 2011;21:579-587.

27 Olson EN, Schneider MD: Sizing up the heart: development redux in disease. Genes Dev 2003;17:19371956.

28 Huang Y, Tsang SY, Yao X, Chen ZY: Biological properties of baicalein in cardiovascular system. Curr Drug Targets Cardiovasc Haematol Disord 2005;5:177-184.

29 Lin L, Wu XD, Davey AK, Wang J: The anti-inflammatory effect of baicalin on hypoxia/reoxygenation and TNF-alpha induced injury in cultural rat cardiomyocytes. Phytother Res 2010;24:429-437.

30 Wiese C, Nikolova T, Zahanich I, Sulzbacher S, Fuchs J, Yamanaka S, Graf E, Ravens U, Boheler KR, Wobus AM: Differentiation induction of mouse embryonic stem cells into sinus node-like cells by suramin. Int J Cardiol 2011;147:95-111.

-31 Ng SY, Wong CK, Tsang SY: Differential gene expressions in atrial and ventricular myocytes: insights into the road of applying embryonic stem cell-derived cardiomyocytes for future therapies. Am J Physiol Cell Physiol 2010;299:C1234-1249.

-32 Fijnvandraat AC, Lekanne Deprez RH, Moorman AF: Development of heart muscle-cell diversity: a help or a hindrance for phenotyping embryonic stem cell-derived cardiomyocytes. Cardiovasc Res 2003;58:303-312.

33 Lyons I, Parsons LM, Hartley L, Li R, Andrews JE, Robb L, Harvey RP: Myogenic and morphogenetic defects in the heart tubes of murine embryos lacking the homeo box gene Nkx2-5. Genes Dev 1995;9:1654-1666.

-34 Tanaka M, Chen Z, Bartunkova S, Yamasaki N, Izumo S: The cardiac homeobox gene Csx/Nkx2.5 lies genetically upstream of multiple genes essential for heart development. Development 1999;126:12691280.

-35 Fijnvandraat AC, van Ginneken AC, de Boer PA, Ruijter JM, Christoffels VM, Moorman AF, Lekanne Deprez RH: Cardiomyocytes derived from embryonic stem cells resemble cardiomyocytes of the embryonic heart tube. Cardiovasc Res 2003;58:399-409.

-36 Durocher D, Charron F, Warren R, Schwartz RJ, Nemer M: The cardiac transcription factors Nkx2-5 and GATA-4 are mutual cofactors. EMBO J 1997;16:5687-5696.

-37 Lee Y, Shioi T, Kasahara H, Jobe SM, Wiese RJ, Markham BE, Izumo S: The cardiac tissue-restricted homeobox protein Csx/Nkx2.5 physically associates with the zinc finger protein GATA4 and cooperatively activates atrial natriuretic factor gene expression. Mol Cell Biol 1998;18:3120-3129.

38 Small EM, Krieg PA: Molecular regulation of cardiac chamber-specific gene expression. Trends Cardiovasc Med 2004;14:13-18.

-39 Yamagishi H, Yamagishi C, Nakagawa O, Harvey RP, Olson EN, Srivastava D: The combinatorial activities of Nkx2.5 and dHAND are essential for cardiac ventricle formation. Dev Biol 2001;239:190-203.

40 Watabe T, Miyazono K: Roles of TGF-beta family signaling in stem cell renewal and differentiation. Cell Res 2009;19:103-115.

41 Schultheiss TM, Burch JB, Lassar AB: A role for bone morphogenetic proteins in the induction of cardiac myogenesis. Genes Dev 1997;11:451-462.

42 Naito AT, Shiojima I, Akazawa H, Hidaka K, Morisaki T, Kikuchi A, Komuro I: Developmental stage-specific biphasic roles of Wnt/beta-catenin signaling in cardiomyogenesis and hematopoiesis. Proc Natl Acad Sci USA 2006;103:19812-19817.

43 Tran TH, Wang X, Browne C, Zhang Y, Schinke M, Izumo S, Burcin M: Wnt3a-induced mesoderm formation and cardiomyogenesis in human embryonic stem cells. Stem Cells 2009;27:1869-1878.

44 Willems E, Cabral-Teixeira J, Schade D, Cai W, Reeves P, Bushway PJ, Lanier M, Walsh C, Kirchhausen T, Izpisua Belmonte JC, Cashman J, Mercola M: Small molecule-mediated TGF-beta type II receptor degradation promotes cardiomyogenesis in embryonic stem cells. Cell Stem Cell 2012;11:242-252.

-45 Ueno S, Weidinger G, Osugi T, Kohn AD, Golob JL, Pabon L, Reinecke H, Moon RT, Murry CE: Biphasic role for Wnt/beta-catenin signaling in cardiac specification in zebrafish and embryonic stem cells. Proc Natl Acad Sci USA 2007;104:9685-9690. 
46 Zhou QM, Wang S, Zhang H, Lu YY, Wang XF, Motoo Y, Su SB: The combination of baicalin and baicalein enhances apoptosis via the ERK/p38 MAPK pathway in human breast cancer cells. Acta Pharmacol Sin 2009;30:1648-1658.

47 Xu XF, Cai BL, Guan SM, Li Y, Wu JZ, Wang Y, Liu B: Baicalin induces human mucoepidermoid carcinoma Mc3 cells apoptosis in vitro and in vivo. Invest New Drugs 2011;29:637-645.

48 Liu X, Gu J, Fan Y, Shi H, Jiang M: Baicalin attenuates acute myocardial infarction of rats via mediating the mitogen-activated protein kinase pathway. Biol Pharm Bull 2013;36:988-994.

49 Xiping Z, Hua T, Hanqing C, Li C, Zhiwei W, Keyi W, Wei Y, Yun L, Qingyu L, Qing H, Fei W: The protecting effects and mechanisms of Baicalin and Octreotide on heart injury in rats with SAP. Mediators Inflamm 2007;2007:19469.

50 Cao Y, Mao X, Sun C, Zheng P, Gao J, Wang X, Min D, Sun H, Xie N, Cai J: Baicalin attenuates global cerebral ischemia/reperfusion injury in gerbils via anti-oxidative and anti-apoptotic pathways. Brain Res Bull 2011;85:396-402.

51 Cao Y, Li G, Wang YF, Fan ZK, Yu DS, Wang ZD, Bi YL: Neuroprotective effect of baicalin on compression spinal cord injury in rats. Brain Res 2010;1357:115-123.

52 Ge QF, Hu X, Ma ZQ, Liu JR, Zhang WP, Chen Z, Wei EQ: Baicalin attenuates oxygen-glucose deprivationinduced injury via inhibiting NMDA receptor-mediated 5-lipoxygenase activation in rat cortical neurons. Pharmacol Res 2007;55:148-157.

53 Zhang K, Lu J, Mori T, Smith-Powell L, Synold TW, Chen S, Wen W: Baicalin increases VEGF expression and angiogenesis by activating the ERR\{alpha\}/PGC-1\{alpha\} pathway. Cardiovasc Res 2011;89:426-435.

54 Cao N, Liu Z, Chen Z, Wang J, Chen T, Zhao X, Ma Y, Qin L, Kang J, Wei B, Wang L, Jin Y, Yang HT: Ascorbic acid enhances the cardiac differentiation of induced pluripotent stem cells through promoting the proliferation of cardiac progenitor cells. Cell Res 2012;22:219-236. 